\title{
Prevalence of HIV in South Sudan
}

\author{
Article by Etiki John Firstday \\ Master of Public Health, Texila American University, Nigeria \\ E-mail: jonfirst4christ@gmail.com
}

\begin{abstract}
Human immunodeficiency virus (HIV) is the virus that causes AIDS. It attacks the body's immune system by weakening the human body's defence against disease and consequently makes one vulnerable to a number of potentially life-threatening infections and cancers. HIV is transmitted through exposure to infected blood and blood products and from infected mother to child during childbirth. This study is a cross sectional study on HIV Prevalence in South Sudan. The study reveals a prevalence rate of $2.7 \%$ for the whole country and about $14 \%$ in some areas with the most vulnerable being between the ages of 15 to 49. It also reveals that social factors like poverty and prevailing gender relations contribute to infection and reinfection among People Living with AIDS and their partners. This study identified that Non-Governmental Organizations (NGO) and the United Nations (UN) are key in the fight against HIV in South Sudan; as the Government of South Sudan (GOSS) is battling with basic life need such as food and shelter for the population of South Sudan. There is therefore a need for a renewed campaign against HIV/AIDS.
\end{abstract}

Keywords: HIV, AIDS, Prevalence, NGO, UN, GoSS

\section{Introduction}

HIV (human immunodeficiency virus) is a lentivirus (a subgroup of retrovirus) that causes HIV infection and acquired immune deficiency syndrome (AIDS). (Fauci, A., S., \& Lane, H.,C., 2005). AIDS is a condition in humans in which progressive failure of the body defence system thus allowing life-threatening opportunistic infections and cancers to thrive. If untreated average survival time after infection with HIV is estimated to be 9 to 12 years, determined by the HIV subtype (Wikipedia, 2015). HIV will almost always deplete the immune system, if untreated; leaving the body vulnerable to one or more life-threatening diseases that normally do not affect healthy people. This stage of HIV infection is called AIDS, or acquired immunodeficiency syndrome. The more the immune system has been damaged, the greater the risk of death from opportunistic infections (infections that take advantage of weaknesses in the immune defences). Experts agreed on the term AIDS in the early 1980 s, before the discovery of HIV, to describe the then new syndrome of profound immune suppression. Today, AIDS is understood as the latter stage along a continuum of HIV infection and disease (UNMISS.2015).

As a country battered with a long years of civil war and chequered migration history, the history of HIV in South Sudan is not well established. HIV epidemiology in South Sudan is poorly documented and also certainly in a state of rapid change (SSMJ, 2015). The Comprehensive Peace Agreement (CPA) that brought about peace after decades of war, displacement and isolation ushered in a period of normality which will have great impact on a wide spectrum of disease conditions and not least HIV/AIDS. The UNGASS report of 2008 gives the adult HIV prevalence in South Sudan as 3.1\%; with a population estimate of 10 million translating into 155,000 adults living with HIV/AIDS. This contrasts with a prevalence of $1.6 \%$ adults in North Sudan. (Sudan Medical Journal, 2009).

The UN have been active in the fight against HIV/AIDS through the MDG goal. The UN system is actively engaged in the response to AIDS. UN leadership on AIDS has been spear headed by the Joint United Nations Programme on HIV/AIDS (UNAIDS), which consists of a Secretariat and 10 cosponsoring agencies from within the system (UNAIDS, 2015). HIV is one of the Millennium 
Development Goals, and progress in responding to the epidemic will also be required to ensure achievement of other Millennium Development Goals.

The UN system monitors the epidemic to alert the world to the magnitude and nature of the situation, to detect important new trends, and to help countries determine whether their efforts are succeeding in bringing the epidemic under control. The activities have taken on particular importance following the 2001 global agreement at the UN General Assembly on the Declaration of Commitment to HIV/AIDS and the 2006 Political Declaration on HIV/AIDS, which require Member States to report periodically on progress made in the combat against the epidemic. (Munywoki, 2008). The 2008 High-level Meeting on AIDS reviewed the progress made on implementing the declarations. The UN system provides guidance in helping countries to achieve universal access to prevention, treatment, care and support for people living with or affected by HIV, a goal set in the 2006 Political Declaration. By collecting and disseminating best practices, the UN system helps to ensure that programmes and policies to achieve universal access to prevention, treatment, care and support are based on the strongest available evidence of what is effective. The UN system encourages and often sponsors cutting-edge research to improve the ability of countries and communities to mount effective efforts to curb the epidemic. In respect to HIV in the workplace, for example, the UN Cares 10 Minimum Standards provide guidance for personnel in the UN, and the ILO Code of Practice on HIV/AIDS and the World of Work provides guidance for employers throughout the world, including the UN system.

With a presence in almost all low- and middle-income countries, the UN helps countries through its joint support programmes developed by Joint UN Teams on AIDS to develop and implement effective AIDS strategies. The UN system works with governments, civil society, including people living with $\mathrm{HIV}$, the private sector, faith-run organizations and external donors to strengthen national responses under a framework called the "Three Ones". The "Three Ones" are a set of principles that advise that all countries have ONE national AIDS coordinating authority, ONE agreed framework to address the epidemic, and ONE national monitoring and evaluation system. Above all, the UN system advocates an extraordinary response to the unprecedented challenge posed by AIDS.

The study therefore seeks to reveal the prevalence of HIV in South Sudan, the effect of HIV on South Sudan economy, and the role of NGO such as UN, UNAID in combating HIV in South Sudan.

\section{Methods}

A systematic literature review on HIV and its prevalence in South Sudan was done. Databases of the UN, UNAIDS and other academic websites were consulted in search for the required information. A rapid examination was conducted applying qualitative and cross sectional study. Information was equally collected through documentation, observation from IDP camps as well as rapid assessment of several IDP camps in South Sudan.

\section{Results}

The systematic search in the various database showed the prevalence of HIV in South Sudan. The various effects of HIV on the economy and its demography was equally noted accordingly.

The UNGASS report of 2008 gives the adult HIV prevalence in South Sudan as 3.1\%; with a population estimate of 10 million translating into 155,000 adults living with HIV/AIDS. This contrasts with a prevalence of $1.6 \%$ adults in North Sudan. (Sudan Medical Journal, 2009).

\section{South sudan healthcare system and HIV management}

With over 40 years of civil war with the Northern Sudan, and the global fall in oil prices, South Sudan has got one of the weakest health sector in the world today. HIV management therefore depends on foreign donor agencies (UNAIDS, 2008). This makes the health system to be at the mercy of foreign donors. Just about 3.6\% of South Sudan's populations are living with HIV and the GoSS has little it can do to help through its Ministry of Health due to poor health budget. 


\section{the negative impact of HIV on south sudan economy}

HIV/AIDS is a health, economic and security related issue. The government of South Sudan has made a start in addressing this epidemic through the formation of the South Sudan AIDS Commission. HIV has a capacity to crippling any nation's economy if it is not well managed (. However, even when well managed it remains an economic burden to every country especially economically weak countries like South Sudan. Both those infected and affected are usually under burden of financing the delicate lives of the PLHA. (WHO Report, 2015).

Appropriate supportive statements have been made by the President of South Sudan, and the Vice President publicly undertook an HIV test. These are important beginnings of a comprehensive response to what can easily spiral into a devastating epidemic (Seeley, 2011).

\section{Effects of war and famine on HIV patients in south sudan}

A deadly surge in violence in South Sudan resulting in massive population displacement and also resulting in tens of thousands in dire need of emergency medical care. PLHA were also affected: with many abandoning their locations to places where they cannot access drugs and good foods/balanced diets. This austere condition resulted (resulting) in massive deaths due to AIDS related situations. Thus, the UNAIDS is concerned about the dire situation faced by the growing South Sudanese refugee population in IDP camps/clusters inside the country.

The UN joint programme (UNJP) remains deeply committed to meeting the humanitarian needs of the people of South Sudan, and urge the international community and other stakeholders to join in the efforts to curtail the imminent famine due to abandonment of agriculture by the people of South Sudan. War and famine usually go together resulting in difficulty in accessing balanced diet requisite for a healthy life and an immune booster for PLHA.

\section{HIV and poverty rates in south sudan}

$52 \%$ of the population live below the national consumption poverty line. Poverty is significantly lower in urban areas where only $25 \%$ of population live below poverty line compared to $56 \%$ in rural areas. Poverty index is higher in female-headed households, rated at $58 \%$, compared to $47 \%$ for men headed households. In a bid to make ends meet, prostitution and all kinds of sexual trading go on resulting in higher incidence of HIV among the poor. Also lack of education makes the indigent population unable to go to school and acquire the knowledge needed to avoid risky sexual behaviour.

Education is also a key determinant of poverty with $12 \%$ of households with a head having postsecondary education living in poverty compared to $57 \%$ of households where the head has no education. Given that poverty is a key determinant in access to health services, households headed by women and people with no education are likely to have difficulties accessing HIV services. In addition to high levels of poverty, South Sudan has a high disease burden and low levels of education, thus ranking as one of the poorest countries in the world.

\section{Anti retroviral therapy in south sudan demography}

Due to the ravaging war in South Sudan, ART access are only accessible within areas that donors consider safe with respect to security. This makes it difficult for people outside of Juba to be able to access their drugs leading to more HIV/AIDS related deaths in the states outside of the capital Juba. Achieving the vision of absolute zero new HIV infections, zero discrimination and zero AIDS-related deaths requires that everyone needing HIV treatment has access to life-saving medication and access to HIV prevention services. Antiretroviral therapy is one of the most effective tools available and it is an essential part of an efficient, sustainable AIDS response. Antiretroviral therapy (ART) averted 7.8 million deaths in low- and middle-income countries from the peak in 1995 until 2014 most especially in Sub-Saharan Africa. The many advantages of ART includes; the prevention of new HIV infections, reduction of the risk of HIV transmission by up to ninety six percent, prevention of illness, reduction 
of the risk of tuberculosis infections among people living with HIV by sixty five per cent. (http://www.who.int/hiv/topics/treatment/en, 2016)

\section{Internally displaced persons and HIV}

Internally displaced persons and migrant groups tend to have sexual partners often among themselves; as a result the greater risk of transmission of HIV is internal. Moreover, in other circumstances the risk of external transmission increases as in the situation of single displaced men who are employed in low status jobs and who tend to have multiple partners and commercial sex. Also IDP women have been forced to engage in commercial sex because of the poverty and economic situation. (IOM Report, 2016). These two situations are particularly true for the displaced population in all the states of South Sudan. Due to the great vulnerability of the refugees/displaced population to HIV/AIDS the absence of sufficient political will to deal with the epidemic can result in particularly higher HIV/AIDS prevalence among these groups. The economic state of the country largely affects HIV prevalence as poverty drives people to a lot of risky behaviours like prostitution etc.

\section{Healthcare system and socio-dynamics of south sudan}

South Sudan healthcare is just at the elementary stage of service provision; this is because more than half of the country population has no access to good health care. Also the social status which is determined by the economic status of the different people of the country has a great role in the kind of healthcare accessible to the individual. The healthcare system is propped by external donor agencies. (http://www.hpfsouthsudan.org/health-systems-strengthening/, 2016)

\section{HIV and illiteracy in south sudan}

From the national levels in Africa there is a positive correlation between literacy rates and HIV infection rates. More literate countries tend to have higher rates of HIV infection. More literate African countries tend to be the most developed on the continent and they share a number of features that make them vulnerable to higher rates of HIV infection. Firstly, the most developed countries often have the largest income disparities between men and women, which is a factor associated with HIV infection rates (World Bank, 1997). Similarly, employments in the formal sector are associated with HIV infection. (Barongo, Borgdorff, Mosha, Nicoll, \& al., 1992; Serwadda et al., 1992). In South Sudan literacy rate is just about $25 \%$ which explains why the HIV prevalence is seemingly low.

\section{United nations support to south sudans combats with HIV}

The obvious situation in South Sudan is characterized by a fragile peace, lack of infrastructure and basic services, a depressed economy, and nascent government and rule of law structures with significant and urgent capacity building needs. Translating the Comprehensive Peace Agreement of 2005 into actions and programmes that will facilitate sustainable post conflict recovery, government, and delivery of services has been an immense challenge to the GoSS. Presently, the World Bank, an agency of the UN is assisting South Sudan Aids Commission (SSAC) in its technical capacity to facilitate the implementation of the MTDF for HIV/AIDS project, which was developed in consultation with representatives of GoSS, UN Agencies, Civil Society, and other key development partners. From this end the World Bank is supporting SSAC to review and update the draft HIV M\&E framework and the result framework for the MDTF-supported HIV project and the implementation plan. Goss and health workers are committed to finding ways of providing HIV prevention and treatment services to internally displaced people in the UNMISS sites. Humanitarian organizations and United Nations agencies, including UNMISS, UNAIDS and the Office for the Coordination of Humanitarian Affairs, provides technical and financial support to open an additional primary healthcare centres, where HIV testing and counselling services are available.

These organizations also advocates the installation of a CD4 machine at the United Nations Hospital in the Malakal (Upper Nile States) camp to help health workers monitor the viral loads of PLHA. 


\section{Discussion}

Based on the data reviewed, it shows that the prevalence of HIV in South Sudan is pegged at $3.1 \%$ according to the UNGASS report of 2008. In another report it stated that the prevalence rate is high and stands at $2.7 \%$ for the whole country and in some areas it is up to 14 percent with the age group most affected being individuals between the ages of 15 to 49 . This alarming rate calls for renewed action in the fight against HIV/AIDS. South Sudan might have to deal with an epidemic in ten years if HIV prevalence is not addressed adequately. (UNGASS, 2015)

Due to the poor healthcare system in South Sudan which resulted from civil war which ravaged the country, the country has very little assistance to offer to people living with HIV/AIDS. They depend heavily on foreign donors for assistance.

If HIV/AIDS is not adequately tackled, it has the tendency of crippling the economy. South Sudan being an economically weak country, HIV remains a burden to its economy. Therefore curbing the menace is very tantamount to saving the economy. Also $57 \%$ of the Sudans lives below the poverty line. Poverty is higher in households headed by females, rated at $58 \%$ compared to $47 \%$ for households headed by men. It's worthy to state that education and poverty is interrelated, therefore, households headed by educated people suffer less poverty than those who are not educated. Owing to the fact that poverty is a key determinant in access to health services, households headed by uneducated males and females are likely to have difficulty in accessing HIV services. South Sudan in correlation to the stated facts has high levels of poverty, therefore, access to HIV services may be difficult.

Observations from IDP camps revealed that internally displaced persons have sexual partners among themselves which makes transmission of HIV an internal one. However, IDP women are at greater risk of being infected with HIV due to forceful engagement in commercial sex work. These situations are particularly true for the displaced population in all the states of South Sudan. The prevalence of HIV among these group of people is very high. Also the economy of the country equally drives a lot of people to engage in risky behaviours such as prostitution.

There is a great aid from the international donors to South Sudan to help curb the menace of HIV/AIDS. Presently, the World Bank, an agency of the UN is assisting South Sudan Aids Commission (SSAC) in its technical capacity to facilitate the implementation of the MTDF for HIV/AIDS project, which was developed in consultation with representatives of GoSS, UN Agencies, Civil Society, and other key development partners. Humanitarian organizations and United Nations agencies, including UNMISS, UNAIDS and the Office for the Coordination of Humanitarian Affairs, provides technical and financial support to open an additional primary health-care centres, where HIV testing and counselling services are available.

\section{Recommendations and conclusions}

The presented findings is part of a larger research project to evaluate the prevalence of HIV in Southern Sudan. Hence, this study did not examine whether some of the concepts used in HIV (e.g., random sampling) was appropriate for use in South Sudan. This will be determined in the next phase of my study.

Nevertheless, there is high HIV prevalence in South Sudan and AIDS-related stigma in local communities. The impact of such stigma leads to non- disclosure of status by carriers. A broader social context such as poverty and prevailing gender relations also contribute to infection and reinfection among people living with HIV/AIDS.

It is therefore recommended that for reduction in the prevalence of HIV in South Sudan the following should be done by the Government of South Sudan (GoSS);

(i) GOSS should expand coverage, diversify approaches and intensify effort to end emergent HIV

(ii) Commit to redouble HIV-prevention efforts by taking all measures to implement comprehensive, evidence-based prevention approaches, taking into account local circumstances, 
ethics, cultural values, including through, but not limited to: conducting public awareness campaigns and targeted HIV education to raise public awareness about HIV; harnessing the energy of young people in helping to lead global HIV awareness (Kenny, 2009)

(iii) Reduction in risky behaviour by encouraging responsible sexual behaviour, abstinence, fidelity and consistent and correct use of condoms (Kaiser et.al, 2006).

(iv) Increasing access to essential commodities like male and female condoms and sterile injecting equipment.

(v) Ensuring that people, especially young people, have the means to exploit the potential of new modes of connection and communication. (Asego, 2008).

(vi) Significantly increasing and promoting voluntary and confidential HIV testing and counselling as well as provider-initiated HIV testing and counselling.

(vii) Increasing national testing promotion of HIV campaign and other sexually transmitted infections (Munywoki, 2008)

(viii) Giving consideration, appropriately, to implementing and expanding risk- and harm-reduction programs, taking into account the WHO, UNODC, UNAIDS Technical Guide meant for Countries to Set Targets for Universal Access to HIV Prevention, Treatment and Care for Injecting Drug Users.

(ix) Encouraging male circumcision.

\section{Acknowledgement}

I acknowledge God Almighty for the strength he gave me to finish this work.

\section{References}

[1] Abebe, Y. et al. (2003). HIV prevalence in 72,000 urban and rural male army recruits, Ethiopia. AIDS, 17:1835-1840.

[2] Adlington, R., \& Burnett, A. (2014). Sexually transmitted infections as a consequence of rape. In: Peel, M. ed. Rape as a method of torture. (2014) London, Medical Foundation for the Care of Victims of Torture: AIDS, Security and Conflict Initiative (2015). HIV/AIDS, security and conflict: new realities, new responses. New York, Social Science Research Council (SSRC) and the Netherlands Institute of International Relations, AIDS, Security and Conflict Initiative (2011) Retrieved from : http://asci.researchhub.ssrc.org, accessed.

[3] AIDS, Security and Conflict Initiative [web site] (2011). New York, AIDS, Security and Conflict Initiative. Retrieved from : http://asci.researchhub.ssrc.org, accessed. Aging in Stride (2016). Retrieved from:http://aginginstride.enewsworks.com/en/12/articles/263/Seniors-and-HIVAIDS-the-Statistics-Might-

Surprise-You.htm

[4] Anastario, M.P., Tavarez, M..I \& Chun H. (2010) Sexual risk behaviour among military personnel stationed at border-crossing zones in the Dominican Republic. Revista Panamericana de Salud Pública/Pan American Journal of Public Health. (2015)

[5] Asego, J. (2008). Youth in participatory education theatre against HIV/AIDS in Juba, South Sudan. XVII International AIDS Conference.

[6] Ba, O. et al. (2008). HIV/AIDS in African militaries: an ecological analysis. Medicine, Conflict and Survival.

[7] Baliunas, D. et. al. (2010). Alcohol consumption and risk of incident human immunodeficiency virus infection: a meta-analysis. International Journal of Public Health.

[8] Barnett. T., Dutta, I. (2008). HIV and state failure: is HIV a security risk? New York, AIDS, Security and Conflict Initiative.

[9] Barnett, T., Prins, G, (2006). HIV/AIDS and security: fact, fiction and evidence; a report to UNAIDS. International Affairs.

[10] Barnett, T.\& Weston, M. (2008). Health, wealth, HIV and the economics hope. AIDS, 2(Suppl.

[11] Chirambo, K. \&Steyn, J. (2009) AIDS and local government in South Africa. Pretoria, Institute for Democracy in South Africa.

[12] Commission on Social Determinants of Health. (2008). Closing the gap in a generation: health equity through action on the social determinants of health. Final report of the Commission on Social Determinants of 
Health. Geneva, World Health Organization (http://www.who.int/social_determinants/resources/gkn_lee_al.pdf, accessed 17 August 2010).

[13] Cornman, D.,C. (2010). Behavioural HIV prevention interventions [slide presentation]. 2010 DPKO. (2010). Monthly summary of military and police contribution to United Nations operations. New York, United Nations. Retrieved from :http://www.un.org/en/peacekeeping/contributors/06-08.shtml.

[14] Fauci, A.,S., \& Lane, H.,C.,(2005). Human immunodeficiency virus disease: AIDS and related disorders. Harrison's Principles of Internal Medicine 16th Edition. New York, McGraw-Hill Medical Publications Division http://www.unaids.org/Epi2008/doc/report_pdf.html.

[15] G8 (2008). Progress report by the G8 Africa Personal Representatives (APRs) on implementation of the Africa Action Plan. Tokyo, Group of 8 (G8) industrialized countries (http://www.mofa.go.jp/POLICY/economy/summit/2008/doc/pdf/0708_10_en.pdf, Accessed) 15 April 2011.

[16] Graeme, J.,S., Irvine, S.,S., Scott, M., \& Kelleher, A.,D., et. al. (1997). Strategies of care in managing HIV. In Managing HIV. Sydney: Australasian Medical Publishing Company Limited 1997.

[17] International Centre for Ethnic Studies (2009). A survey of HIV/AIDS awareness and risky sexual behaviour in a vulnerable population in Sri Lanka. New York, AIDS, Security and Conflict Initiative (ASCI Research Report No. 22).

[18] Iqbal, Z., Zorn, C., (2010). Violent conflict and the spread of HIV/AIDS in Africa. Journal of Politics.

[19] Karutu, C., \&McMahan (2008). Gearing up the Southern Sudanese military to prevent HIV/AIDS. [refWEAE0404] XVII International AIDS Conference.

[20] Kitahata, M.,M., Koepsell, T.,D., Deyo, R.,A., \&Maxwell, C.,L., et.al. (1996). Physicians experience with the acquired immunodeficiency syndrome as a factor in patients' survival. N Engl.J Med 1996.

[21] Kaul, I., Grunberg, I., \& Stern M, eds. (1999). Global public goods: international cooperation in the 21st century. New York, Oxford University Press.

[22] Kenny, L. (2009). Towards universal access to integrated HIV prevention, treatment, care and support: militaries and other uniformed services [slide presentation]. 38th International Congress on Military Medicine, Geneva, UNAIDS.

[23] Kershaw, R.J. (2008). The impact of HIV/AIDS on the operational effectiveness of military forces. New York, AIDS, Security and Conflict Initiative (ASCI Research Report No. 4; http://asci.researchhub.rc.org/working-papers/Kershaw.pdf, accessed 15 April 2011).

[24] Kruijt, D. \&Balconi, J. (2008). HIV/AIDS and the Central American uniformed services. New York, AIDS, Security and Conflict Initiative. ASCI. Research Report No. 3. Retrieved from : http://asci.researchhub.ssrc.org/hiv-aids-and-the-central-american-uniformed-services/attachment, accessed.

[25] Kusasira, S. (2010). The importance and implications of knowing the HIV epidemic in the military: the Uganda Peoples' Defence Forces [slide presentation].

[26] Kaiser, R., Kedamo, T., Lane, J., Kessia, G., \& Downing, R., et.al. (2006). HIV, syphilis, herpes simplex virus 2 and behavioural surveillance among conflict-affected populations in Yei and Rumbek, Southern Sudan. AIDS.

[27] Likimani, S. (2007a). Medical and public health implications of HIV and AIDS in peacekeeping: field evaluation and analysis. Unpublished, DPKO.

[28] Likimani, S. (2007). Some implications of HIV at peacekeeping missions [slide presentation]. DPKO Training Workshop on HIV/AIDS, Brindisi, Italy. (2007).

[29] Lowicki-Zucca, M., \& Karmin S, Dehne K-L (2009). HIV among peacekeepers and its likely impact on prevalence on host countries' HIV epidemics. International Peacekeeping.

[30] Munywoki, M. (2008). HIV and AIDS in a peacekeeping scenario: the case of Sudan. [ref XVII International AIDS Conference 2-8 August 2008.

[31] Marilynn, M. (2007). New York Times. Retrieved from: http://www.nytimes.com/2007/08/22/health/22iht-22sex.7216942.html?_r=0MilitaryHIV/AIDS Conference, Arusha, United Republic of Tanzania (2010).

[32] McCarthy, M.,C., Khalid, I.,O., \& El Tigani (2008). A. HIV-1 infection in Juba, Southern Sudan. J of Med Virol 1995;46:18-20. 
Texila International Journal of Public Health

Volume 4, Issue 4, Dec 2016

[33] Rawls, J. (1993). Political liberalism. New York, Columbia University Press.

[34] Sato, A. (2008). Is HIV/AIDS a threat to security in fragile states? New York, AIDS, Security and Conflict Initiative, Social Science Research Council (ASCI Research Report No. 10).

[35] Secretary-General of the United Nations. (2009). Women and peace and security: report of The SecretaryGeneral. New York, United Nations (S/2009/465).

[36] Garrett, L. (2005). HIV and national security: where are the links? New York, Council on Foreign Relations.

[37] Seeley, J. (2011). The longitudinal impact of HIV/AIDS on agriculture and rural livelihoods in Uganda: framing paper. Swindon, Economic and Social Research Council. Conclusion and recommendations 67

[38] Seeley, J., Dercon, S. \& Barnett, T. (2010). The effects of HIV/AIDS on rural communities in East Africa: a 20-year perspective. Tropical Medicine and International Health.

[39] Sen, A. (1999). Development as freedom. New York, Alfred A. Knopf. Sexual Violence Research Initiative. (2007). Sexual violence and HIV. Pretoria, Sexual Violence Research Initiative.

[40] Barongo, Borgdorff, Mosha, \& Nicoll et.al. (1992). Employments in the formal sector associated with HIV infection.

[41] Serwadda, et. al. (1992). Employments in the formal sector associated with HIV infection.

[42] Shuper, P.A., et al. (2009). Alcohol as a correlate of unprotected sexual behaviours among people living with HIV/AIDS: review and meta-analysis. AIDS Behavior, 13:1021-1036.

[43] Sommers, M.S. et al. (2006). The effects of age and ethnicity on physical injury from rape.

[44] Sudan Tribune (2016). The menace of AIDS in South Sudan. Retrieved from: http://sudantribune.com/spip.php

?mot676.United Nations Medical Directors (2008). Position statement on HIV/AIDS. New York, United Nations Medical Directors (2008).

[45] Africa news (2016). Retrieved from: http://www.africanews.com/2016/03/03/south-sudan-s-hivprevalence-may-lead-to-an-epidemic-unaids/

[46] UNAIDS, AIDS. Epidemic update: June 2008. UNAIDS (2008). Retrieved from: http://www.unaids.org/Epi2008/doc/report_pdf.html.

[47] UNGASS HIV/AIDS in Northern Sudan. UNGASS Report January 2008.

[48] UNGASS HIV/AIDS in Northern Sudan. UNGASS Report January 2015

[49] WHO (2015). Antiretroviral therapy for HIV infection in adults and adolescents in resource-limited settings-towards universal access.

[50] WHO Report (2016). Antiretroviral therapy. Retrieved from: http://www.who.int/hiv/topics/treatment/en/

[51] World Health Organization. (2007) WHO Case Definitions of HIV for Surveillance and Revised Clinical Staging and Immunological Classification of HIV-related disease in Adults and Children.

[52] Wegbreit, J., Bertozzi, S., DeMaria, \& Padian, N.,S. (2006). Effectiveness of HIV prevention strategies in resource-poor countries: tailoring the intervention to the context. AIDS 2006;20:1217-1235.

[53] Wambua, P., Kay, A., Atsbeha, T., Khamis, G. (2007). Key findings from a qualitative BCC formative assessment study in Western Equatoria state, Southern Sudan, December 2007. [refTHPE0496] XVII International AIDS Conference 2-8 August 2008. 